\title{
THE MINISTERIAL TASKFORCE ON NURSING: A STRUGGLE FOR CONTROL
}

\author{
Jill Wilkinson, RN, PhD, MCNA(NZ), Senior Lecturer, \\ School of Health \& Social Services, Massey University, Wellington
}

\begin{abstract}
It is now ten years since the Ministerial Taskforce on Nursing released its report identifying the barriers that prevented nursing from realising its full potential. A key recommendation was the development of advanced clinical nursing roles that went beyond traditional and institutional boundaries. The constitution and work of the Taskforce is traced in this study, along with the struggle that arose between nursing groups for power to control the future of advanced nursing practice. The convergence of political discourses with those that were dominant in nursing during this period produced considerable tension and contributed to the eventual withdrawal of New Zealand Nurses Organisation representation from the Taskforce membership.
\end{abstract}

Key Words: Nurse practitioner, politics, autonomy, unionism.

\section{Introduction}

In August 1998, the Ministerial Taskforce on Nursing released a report detailing its response to obstacles the nursing profession faced in realising its full potential. The overriding concern of the Taskforce members was to recommend ways to enhance the capacity of nurses to improve access to health services. A key recommendation was the development of advanced clinical nursing roles that went beyond traditional and institutional boundaries. These advanced nursing practice roles would include prescribing rights, access to diagnostic and laboratory testing and direct specialist referral. The Taskforce identified substantial attitudinal, structural, legislative and health purchasing barriers to the development of advanced nursing roles. Their recommendations, however, did not arise from a unified nursing voice. Rather, a struggle within nursing arose over the power to control its future.

Drawing on a recent research project (Wilkinson, 2007), this article traces the constitution and work of the Taskforce. The withdrawal of the New Zealand Nurses Organisation (NZNO) from the Taskforce following the second draft of the report highlighted the divisions present within nursing. Eventually, a consensus position was reached, making space for the consequent construction of the most expert nurse, the nurse practitioner. The manner in which consensus was reached is examined in a second article, also in this issue of Nursing Praxis in New Zealand.

Wilkinson, J. (2008). The Ministerial Taskforce on Nursing: A struggle for control. Nursing Praxis in New Zealand, 24(3), 5-16. 


\section{Research Approach}

The research from which these two articles have been developed draws on a variety of texts chosen from published literature that illustrate particular discursive positions. Transcripts of interviews conducted with individuals who have been influential in the unfolding of the nurse practitioner role in New Zealand have also been used. Approval for the study was obtained from the Massey University Human Ethics Committee.

A discourse analytical approach, informed by the work of Michel Foucault, was used to examine the historical forces at play both inside and outside nursing during the late 1990s in New Zealand. Discourses, as explained by Foucault (1977), are bodies of knowledge construed to be 'truth' and connected to power by reason of this assumption, serving to fix norms and making it virtually impossible to think outside them.

A discourse of autonomy is evident throughout this article and the next and refers not only to clinical autonomy, but also educational practices situated at post-graduate level. Educational emphasis is placed on the individual's development of critical analysis and synthesis of practice, research and leadership, to construct an autonomous practitioner who is most expert in his or her particular scope of practice. The combination of research, advanced education, practice experience and ability (Adams et al., 1997; Paterson, 1987), marks a professionally selfdetermined and expanded scope of nursing.
In contrast, a discourse of unionism refers to a coherent system of discursive practices associated with the Trade Union movement. As such, nurses are represented not only as a workforce, but also as members of a democratic organisation with collective worker rights. Importantly, nurses are constituted under the normalising influence of the collective, to which the interests of the individual are subordinate. The 'rank and file' of union membership depicts conformity as a central value of unionism. Having their roots in revolutionary Marxism, unions are associated with battle metaphors of victory, defeat and militant strike action (Deeks, Parker, \& Ryan, 1994).

Thus the route to professional selfdetermination differs as each discourse positions nurses and nursing in subjectivities that conflict: autonomy privileges the individual and his or her attainments and specific contributions to health-care needs; unionism privileges the collective strength of its membership and improved health services via a nonexploitative work environment that furthers professional development for all nurses.

\section{Ministerial Taskforce on Nursing}

Kathryn Adams (2003, p. 303) reported that towards the end of 1997 , Jenny Carryer Executive Director of the College of Nurses, "approached the then Minister of Health, with a proposal that a high level strategy was needed to resolve the complex matrix of barriers impeding the full utilisation of nursing services". As a result, 
the Ministerial Taskforce on Nursing was commissioned in February 1998 by the Minister, in response to the "obstacles to the nursing profession realising its full potential" (Ministerial Taskforce on Nursing, 1998, p. 3). A report was due at the end of May, but an extension of one month was granted to allow for wider consultation ("Nursing taskforce granted a month's extension," 1998). It was followed by another extension until the end of July, 1998 (Oliver, 1998). The tight timeframe was agreed to because of the likelihood of the Minister of Health changing to the finance portfolio before the Taskforce recommendations had been considered.

The precedent of restored professional autonomy to midwives, under the Nurses Amendment Act 1990, ostensibly offered similar possibilities for nursing. Reflecting on midwifery and other health sector changes, a senior politician involved in the health portfolio and interviewed for the study, acknowledged the influence changes to maternity services had on the decision to proceed with a ministerial review:

I was influenced then by my own positive view about changes for midwives and maternity services ... I could see the potential for nursing to go down the same path, but it was reassuring that the nurses seemed more pragmatic. The hurdles were fairly formidable for a nurse to get to the position to be able to do anything that would be even remotely threatening to GPs was a long way. It was a lot more challenging than just a change in funding for one service, as in the case of midwives.
But nurses work in a more complex environment. It wasn't just a matter of one change to one service. I thought then the variety of things that nurses do is much wider and you may be able to expand practice quite significantly in some areas but it would be very difficult in other areas. So a process of change for nurses would be less reliant on political sponsorship than the midwives and more about solving practical problems to do with services and skills one by one. It could never move too far too fast and I understand it hasn't. That's why I felt changes in nursing practice were much less of a threat to doctors than changes in midwife practice.

Jill: So those ideas must have been going around in your head when the proposal for a review came up.

Well the idea of a review didn't seem to me to be that big a deal at the time quite frankly; in retrospect it was. There were some pretty articulate advocates. You have to remember the context at the time. There was some big pressures for changes in service delivery ... there were gaps in primary care nurses could potentially fill, more opportunities than the practice nurse. We had pushed the Health Commissioner (The Health and Disability Commissioner Act, 1994) and the Medical Practitioners Act (1995) through, so there was a lot going on. In the context of all this change, it seemed logical to look at what the largest professional workforce could do (Interview with Senior Politician). 
Changes to maternity services increased the autonomy of midwifery, but were ideologically driven by the neoliberal view of increased consumer choice, which drove the market for particular services. The legislation the above study participant made reference to, intentionally brought a consumer focus to the health services, requiring practitioner accountability for the provision of competent care. Expanding the range of services potentially offered by nurses simply expanded the range of consumer choice, but would do so in a less contentious way than the changes to midwifery had done. That is, nurses seemed less idealistic ('more pragmatic') than midwives and, because of the diversity of nursing practice, were less likely to ever be a credible challenge to medicine because of the 'fairly formidable hurdles' in the way. This politician did not, therefore, anticipate the significance of the Taskforce findings.

\section{Taskforce Membership}

The Minister appointed a nine-member team comprised of a representative from each of the major nursing groups: the College of Nurses, NZNO, Nurse Executives in New Zealand (NENZ), Nurse Educators in the Tertiary Sector (NETS) and the Nursing Council of New Zealand (henceforth Nursing Council). Nursing members were Jenny Carryer, Executive Director of the College of Nurses; Brenda Wilson, Chief Executive of the NZNO; Frances Hughes, Chief Nursing Advisor for the Ministry of Health; Judy Kilpatrick, Nursing Council chairperson and Head of School at the Auckland Institute of Technology, as well as being a member of NETS (Judy Kilpatrick was appointed to the Nursing Council as a NZNO nominee in May 1996); Julie Martin, Manager of Nursing Services at the Health Funding Authority; Denise Wilson, Nurse Consultant at Lakeland Health; and Beth Cooper-Liversedge, Clinical Director of Nursing at Good Health Whanganui and member of NENZ. Non-nursing members were Toni Ashton, Health Economist at the University of Auckland; and the Hon Dame Ann Hercus who was appointed chairperson. Members were selected for their particular skills and attributes, but a 'fair' and united representation was an overriding goal. Commenting on the Taskforce constitution, a study participant recalls the tension between the NZNO and the College at the time:

There was a sort of an agreement from the main organisations to try and get someone from every main organisation on the Taskforce, so that we could present a united front. Because as you know our history was, if we can shoot each other publicly, lets do so. So there was a very genuine attempt to have a united voice.

Jill: Do you think the NZNO felt that way?

They certainly didn't at the end. And I'm not sure they even did at the beginning. I think they came on reluctantly. It was in a period of absolute mistrust. NZNO didn't like the College; they didn't like the College of Midwives. Those organisations didn't like NZNO. It was an abrasive organisation. Things were confrontational (Interview with NCNZ). 
The Taskforce genesis was not, however, bipartisan, in the sense that the approach to the Minister originated directly from the College of Nurses without reference to the NZNO. Its unilateral inception secured transcendence and a dominant voice in the Taskforce membership for the College, despite the appearance of being representative of the major organisations. Representatives from organisations other than the NZNO were also College advocates and members as senior nurses and academics (Carryer, Denise Wilson, Martin, Cooper-Liversedge, Hughes and Kilpatrick) and gave the College a clear majority voice on the Taskforce. The College membership was perhaps 800 at the time, compared to a declared membership of the NZNO of 26,000 (O'Connor, 1998), but secured only one member on the Taskforce team. As the country's largest professional organisation, the NZNO anticipated having a greater sway than other Taskforce members and stated that "No other taskforce representative can claim that [membership] mandate" (Wilson, 1998, p. 2). Furthermore, the NZNO's historical position as sole nominator to government and nursing advisory committees was severely compromised; a threat that re-emerged during the work of the Taskforce under the Health Occupational Registration Acts Amendment (HORAA) 1998, discussed later. The 'deliberate arrangement' (or stacking) of members without active union affiliation, played a role in tactically blocking the unionist discourse of the NZNO. The appointment of members by the Minister could be interpreted as a deliberate strategy to subdue industrialism, which is inherently antithetical to neoliberal politics.

The hasty assemblage of Taskforce membership also jeopardised effective consultation with Maori, ironically the group most disadvantaged by the current health service (Hefford, Crampton, \& Foley, 2005) and most likely to benefit from a more accessible nursing workforce. There was no acknowledgement of the Treaty of Waitangi in the Taskforce terms of reference and the attendant requirements for participation and partnership with Maori (Ministerial Taskforce on Nursing, 1998). However, the Taskforce members considered themselves "bound by the Treaty relationship" (p. 11) and as such, endeavoured to traverse both Maori and non-Maori worlds to negotiate a consultative process that would meet the needs of both. The difficulties encountered are outlined in the preface to the Taskforce chapter on Maori issues and revolve around the inadequate consultation process over selection of the Maori representative from the outset. The Taskforce member to whom leadership on issues for Maori fell, then had the unenviable task of representing Maori interests without a clear mandate from Maori. As a consequence, she attended five of the six hui (gatherings) held throughout the country, without kaumatua (wise experienced members of the whanau) support. The lack of support and recognition of Maori processes were documented in the report:

Concern was also expressed that Maori representatives were often alone ... Often kaumatua and kuia are not part of the representation, yet are essential for the support 
and safety of representatives when walking amongst Maori ... This is interpreted as a seemingly total neglect of the partnership between non-Maori and Maori ... Consultation was seen to be undertaken within a non-Maori framework; this raised concern that, despite the bicultural nature of Te Tiriti o Waitangi, a lack of recognition existed in relation to the differing timelines and processes (Ministerial Taskforce on Nursing, 1998, p. 82).

Privileging a non-Maori frame of reference in terms of timelines and processes, in the interests of expediency, meant Maori tikanga (protocol) was neglected and the pervasive disregard for cultural practices intrinsic to the health sector was paradoxically reproduced. Consequently, "the use of processes that are acceptable and appropriate to Maori for representation and consultation [and] are vital for the achievement of positive health outcomes" (Ministerial Taskforce on Nursing, 1998, p. 82), were subsumed in the more powerful Ministerial process.

\section{Work of the Taskforce}

The Taskforce were charged with the task of recommending "strategies to remove barriers which currently prevent registered nurses from contributing to a more responsive, innovative, effective, efficient, accessible and collaborative health care service for New Zealanders" (Ministerial Taskforce on Nursing, 1998, p. 8). Issues to do with midwifery practice and enrolled nurses were considered outside of this brief, as were issues to do with nurses' pay and working conditions. The recommendations of the Taskforce concerned access to funding, education, research, management and leadership, workforce resourcing, issues for Maori and expanding the scope of nursing by developing new nursing roles. This last concern (addressed first in the report) identified a nurse practitioner role for New Zealand in conjunction with particular tasks traditionally aligned with medicine; those of prescribing medication, ordering diagnostic and laboratory tests and specialist referrals. The Taskforce were clearly influenced by the United States experience of nurse practitioners, referring to overseas literature and also the April publication by Nurse Executives New Zealand (NENZ, 1998), in which the roles of clinical nurse specialist and nurse practitioner for New Zealand were discussed. The NENZ document positions nurse practitioner education at masterate level. Taskforce member Beth Cooper-Liversedge as a member of NENZ helped to develop this document.

Throughout the $1990 \mathrm{~s}$, nurses around the country were being appointed to senior clinical positions with titles such as nurse consultant, nurse practitioner, independent nurse practitioner, neonatal nurse practitioner, clinical nurse specialist and clinical nurse advisor. These titles lacked national consistency and links to levels of education and competence. However, during the 
work of the Taskforce, the Minister announced an Amendment to the Medicines Act 1981 that would provide for limited nurse prescribing. Legislation that would enable nurse prescribing then became a catalyst to defining a consistent advanced role that was not industry driven, but professionally determined:

I don't think that we would have the nurse practitioner title in this country yet if we hadn't started with prescribing. That was a very deliberate strategy from a few of us ... it was a catalyst to defining the role. Because if we hadn't had legislation pending about that we would never have had to designate it to a title. We would have kept a proliferation of undifferentiated titles at employee level rather than at a professionally-owned level (Interview with a Nurse academic).

Linking prescribing to an advanced practice role is described here as 'a very deliberate strategy'. Work on nurse prescribing had been ongoing since at least 1992, and the publication of a public discussion paper written by John Shaw in 1994. The international research about nurse practitioners, referred to in the Taskforce report, describes settings where nurses prescribe and practice with autonomy. The timing of the announcement (International Nurses Day, May 12), rather than the Amendment itself was a surprise, being in many ways a political gesture to give the report credibility, when it otherwise risked being just another report. When asked if the announcement of the Amendment to the Medicines Act influenced the work of the Taskforce, a senior politician interviewed for the study agreed that the timing was controversial, and said:

The risk with a review is that the report is nice but it's just a report and it's too hard to actually change anything as a result of it. The amendment to the Medicines Act gave the review and the thinking behind it some credibility; a political signal that changes could and would happen.

The announcement was controversial, not only because of the challenge to traditional medical jurisdiction, but also because of the level of education necessary for nurses to become competent prescribers. Positioning prescribing within an advanced practice role that was located within a clinical masterate, served to separate the 'elite' mastersprepared nurses from the majority of nurses. This was problematic for the NZNO, who on the one hand, were seeking to acknowledge advanced nursing practice, but on the other, were bound to an egalitarian ethos inconsistent with status differences. The NZNO welcomed the Minister's announcement, although they had envisaged prescribing papers to be "incorporated into a Bachelor degree" (Manchester, 1998, p. 12), the precedent being midwives who are prepared for prescribing in a Bachelor of Midwifery. Nurses as prescribers per se, however, were not the issue; the core issue was the level of education required. It was also controversial to physicians, who are, after all, only prepared as prescribers to bachelor level. 
Points of Contestation: The Power and Authority to Write Nursing

Already in existence were credentialing mechanisms within NZNO to recognise specialist and advanced nursing roles. Nurses submit written evidence demonstrating stipulated criteria, which is reviewed by a board of nominated peers (New Zealand Nurses Organisation, 2003). Within this framework, the need for masterate level education for advanced and specialist roles seemed unnecessary, because the profession already had a process to acknowledge those with extensive clinical experience. Furthermore, the costs of masters-level education were seen as prohibitive for many nurses (NZNO, 1998a) and ran "the risk of becoming elitist because of cost" (O'Connor, 1996, p. 29).

With the credentialing system in place, the NZNO were seemingly well positioned to take on responsibility for professionally recognising an advanced nursing role. This was a crucial issue for the NZNO and was one of the key reasons it withdrew from the Taskforce. A flyer outlining those reasons stated that "NZNO believes the profession must set its own standards in an inclusive and professional manner. NZNO's sections and colleges are an appropriate national structure for recognising and developing advanced practice" (NZNO, 1998a).

Protecting the future interests and survival of the College, the Taskforce recommended the Nursing Council develop, control and enforce competencies for an advanced practice role, shifting the self-regulation debate to the more neutral regulatory authority:

Also the issue that we really fell foul of was the Nursing Council role and that was probably the biggest point of disagreement ... for NZNO. We couldn't safely, the rest of the Taskforce, agree to leave the development of the nurse practitioner role in the hands of the Union, who were currently espousing a strong "education is irrelevant and length of practice is what counts"- it just wouldn't have been tenable. So we tried to lift it to a neutral space which was Nursing Council, arguing that we would all then contribute and consult and work with Nursing Council, but at least it would be a safe, neutral territory and of course that's exactly what's happened. But NZNO could not wear that at the outset because it seemed that was a major challenge to their historical authority (Interview with the College).

The struggle for power to control this important development in nursing was such that it was preferable to shift power to the more 'neutral' Nursing Council, rather than risk it falling into the hands of the union. NZNO maintained the Council was going beyond its jurisdiction into territory belonging instead, to expert clinical nurses. NZNO policy analyst Hugh Oliver, described the Council as "dominant and controlling", stating, "[t]o have control over its own future, the profession needs to organise its affairs in ways which are under the control of nurses themselves and autonomous of political pressures" 
(Oliver, 1998, p. 13). He strongly suggested the existing structures within NZNO, representative of nurses in practice and devoid of political interference, as the place to determine the direction of advanced practice.

These positions illustrate the fundamental difference in values and beliefs between the College (NETS, NENZ and the Council) and the NZNO; between professional autonomy and unionist discourses. Neither of these discourses is mutually exclusive for these organisations, but particular values permit hierarchies where one or other is dominant. The NZNO, however, maintained it was a sham to assert a "dichotomy between professional and industrial issues" (Oliver, 1998, p. 13), as these are entwined with neither privileged. Perhaps, herein lays the difficulty:

That's correct. [The NZNO] couldn't separate union matters, couldn't see it as professional. There was an absolute driver that anything that came - they didn't need the Taskforce - NZNO would solve it. There was a huge grasping for power going on that people actually failed to recognise (Interview with NCNZ).

This speaker identifies 'grasping for power' as the central issue; because of its dual professional and industrial arms, the NZNO considered itself wholly capable of managing both concerns. Beth Cooper-Liversedge (1998, p. 2) wrote following NZNOs withdrawal from the Taskforce:

At the heart of the matter is a power struggle for the 'mandated' leadership of nursing in New Zealand. This is about ownership of the right to control the destiny of the nursing profession and regrettably, is being communicated incorrectly as a practice - theory gap.

Positioning fundamental differences in ideology as a 'practice-theory gap' is insufficient, however, to explain the clash in power that occurred. Had it been as simple as a practice-theory gap, the competencies for advanced practice would have been the subject of contestation and not the approval body:

Nurse practitioner, advanced nursing, was debated at the Taskforce, but the ingredients of that had already been laid down well before then. The issue was never about what do they look like, what do they do? The issue was always about who was the one that was going to approve them (Interview with $\mathrm{MOH}$ ).

The speaker here points out there was little debate about what an advanced nursing role would do, making reference to what had 'been laid down well before then' as the work done by NENZ, in the document on developing and supporting advanced practice roles (Nurse Executives of New Zealand, 1998) and by the Nursing Council on the competencies for advanced nursing practice (Nursing Council of New Zealand [NCNZ], 1998), published in April and May respectively.

The core competencies as they appear in the 1998 Council document are little changed, despite the later addition of two further competencies, so indicating that what the NP would do 
was agreed upon; what was under dispute was who would control the role and by what mechanism - that is to say whether statutory regulation or voluntary credentialing would prevail.

The argument over who would credential advanced nursing practice was complicated by an amendment to the Health Occupational Registration Acts (HORAA, 1998), read under urgency during the work of the Taskforce (the principal Act was the Health Occupational Registration Acts Amendment: Amendments to Nurses Act 1977, 1998). Changes to the nomination of Council members had been signalled in a Ministry of Health discussion document in 1996 (Ministry of Health, 1996). The effect would be to amend the Nurses Act 1977 and change the nomination process for Nursing Council membership, allowing the Minister of Health to appoint all members. Since the Nurses and Midwives Registration Act 1925 the Nurses Organisation (then the NZTNA) had the exclusive right to nominate specified Council members. The amendment represented not only a challenge to NZNO's historical power, but in their view, was undemocratic, as well as being "inappropriate to concentrate the direction of professional practice in a very few, politically-appointed hands" (Wilson, 1998, p. 2).

The aim of the amendment was to give registration bodies more autonomy (New Zealand Parliamentary Debates, 1998, June 17) and with respect to the Nursing Council membership, deleted the requirement for the
Director General of Health (a doctor or delegate) and the Ministry of Education representative, to be Council members. At a time when the Taskforce was recommending the Council regulate advanced practice, the opportunity for the NZNO to influence the Council, via its nominated members, was diminished. The NZNO already had reservations about the Council's role under the Nurses Act to approve programmes of study; now the concern was politicians would, in effect, be in control of nursing education also.

The context of these changes created an extremely hostile environment between the two nursing organisations and by all accounts was highly taxing for all involved. The withdrawal of traditional Ministry support from the NZNO served to establish a relationship of power that permitted other nursing groups to speak on behalf of nursing and to proceed with Nursing Council regulation of an advanced nursing role.

\section{The Withdrawal of NZNO from the Taskforce}

At the end of July 1998, the NZNO withdrew from the Taskforce and endorsement of the second draft of the report. In Kai Tiaki's August editorial, Brenda Wilson outlined the reasons for withdrawing, citing the lack of open debate over the composition, timeframe and consultation aspects of the report (Wilson, 1998). Not all NZNO nurses received the questionnaires sent out by the Taskforce in the March issue of Kai Tiaki due to an erratic printer insertion problem, raising the question of validity of the Taskforce's findings (Bexley, 1998; Gracez, 1998). 
Reflecting a unionist discourse from the outset, NZNO had maintained that nurses' pay, terms and conditions of employment, patient safety and skill mix, access to post-registration education, funding and contracting of health and disability services could not be divorced from the identification of barriers and strategies to enhance nursing practice. According to Wilson (1998), these issues in the NZNO submission were absent from the first draft and minimally present in the second. Yet all of these issues were addressed in the report in the chapter on 'Workforce Resourcing' and others on 'Education' and 'Access to Funding'. Wilson, however, maintained they had been omitted, as had the impact of the Employment Contracts Act 1991, and represented too great a departure from NZNO principles and policies to continue to be involved.

\section{Conclusion}

As a result of the NZNO's withdrawal, an opportunity was lost for a report that reflected a consensus nursing position. The result was not only a lack of buy-in to the final report, but the release of an alternate vision for the future in a document called Building Partnerships (NZNO, 1998b). Any risk of the Taskforce report becoming obscure was ameliorated, however, by the very public display of discord when the NZNO withdrew from the Taskforce team; the consequence of which brought far greater attention to the Taskforce findings than might otherwise have occurred. Nonetheless, an immensely more productive approach for nursing politics in New Zealand, at the time, may have been one of compromise between all parties.

The next article in this issue of Nursing Praxis in New Zealand traces the events that took place to achieve a consensus position. The clash between discourses of autonomy and unionism are examined in more detail as an advanced practice role for New Zealand began to take shape to become what we now understand to be the nurse practitioner role.

\section{References}

Adams, A., Pelletier, D., Duffield, C., Nacy, S., Crisp, J., \& Mitten-Lewis, S. (1997). Determining and discerning expert practice: A review of the literature. Clinical Nurse Specialist, 11(5), 217-222.

Adams, K. F. (2003). A postmodern/poststructural exploration of the discursive formation of professional nursing in NZ, 1840-2000. Unpublished doctoral dissertation. Victoria University of Wellington. Retrieved June 17, 2004, from http://users.actrix.co.nz/kathryn/index. htm.

Bexley, M. (1998). Validity of Taskforce Report questioned [Letter to the editor]. Kai Tiaki Nursing New Zealand, 4(5), 5.

Cooper-Liversedge, B. (1998). Editorial: Ministerial taskforce on nursing. Nursing Praxis in New Zealand, 13(3), 2-3.

Deeks, J., Parker, J., \& Ryan, R. (1994). Labour and employment relations in New Zealand (2nd ed.). Auckland: Longman Paul.

Employment Contracts Act. (1991). New Zealand Government: Wellington.

Foucault, M. (1977). Discipline and punish: The birth of the prison (A. Sheridan, Trans.). London: Penguin. 
